\title{
A nebulosa terapêutica alternativa
}

(TAVARES, Fátima. Alquimistas da cura: a rede terapêutica alternativa em contextos urbanos. Salvador: Edufba, 2012. 226 p.)

Amurabi Oliveira*

E m meio ao heterogêneo universo da chamada Nova Era, um dos aspectos que mais chama a atenção dos pesquisadores diz respeito à questão terapêutica, bem como a centralidade que as técnicas assumem nesse contexto (Oliveira, 2012). Pesquisadores como Amaral (2000) e Bittencourt Filho (2003) apontam que, para aqueles que vivenciam esse universo, mais relevante que a profundidade das mesmas é a pluralidade de experiências (técnicas), o que, em verdade, pode ser bastante questionável, ao se considerar que, para muitos sujeitos e movimentos, a profundidade da experimentação de determinada técnica pesa mais que a pluralidade de experiências (Oliveira, 2011). Nesse universo marcado por uma espiritualidade difusa é que a pesquisa de Fátima Tavares se insere. Seu livro Alquimistas da cura resulta de sua tese de doutorado defendida junto ao Programa de Pós-Graduação em Sociologia e Antropologia da Universidade Federal do Rio de Janeiro, em 1998, tendo sido desenvolvida sua pesquisa de campo nas cidades do Rio de Janeiro e Niterói, além de incursões esporádicas em cidades próximas.

Seu trabalho recai sobre os terapeutas não médicos, cuja denominação demarca as tensões nas quais esses profissionais estão inseridos, pois, por um lado, buscam afastar-se dos médicos convencionais e, por outro, das referências mágico-religiosas. Ao longo do trabalho percebemos uma tendência contínua por uma busca pela legitimidade que se assenta, sobretudo, na afirmação dessas terapias, assumidamente holísticas, como científicas. Todavia, a autora nos esclarece que, ainda que possamos pensar o referencial de ordem científica e o mágico-religioso como modelos limites, aos quais os terapeutas não médicos ao mesmo tempo se aproximam e se afirmam de forma contrastiva, os arranjos e as possibilidades são múltiplos, em especial considerando a variedade de técnicas utilizadas e os próprios arranjos pessoais.

Mesmo diante da heterogeneidade que se apresenta quanto às práticas, há uma unidade que se apresenta discursivamente, que diz respeito ao holismo, ainda que esse também possa apresentar-se de formas diversas. A ideia de que o ser humano precisa ser compreendido e tratado como totalidade física/psíquica/emocional perpassa

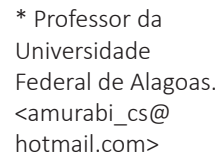


o discurso dos diversos terapeutas alternativos, assim como a ideia que a doença é ocasionada por um desequilíbrio energético, e que, portanto, a cura se relaciona ao reequilíbrio que deve ser buscado por meio das técnicas terapêuticas que possibilitariam o realinhamento da vibração.

Nessa rede alternativa, a questão terapêutica mostra-se central, ou, nos dizeres da autora, "a palavra 'terapêutica' constitui uma moeda forte na legitimidade da especialidade do trabalho desenvolvido pelo profissional da rede alternativa" (p. 53). A impressão que o trabalho nos passa é que este profissional coloca-se, o tempo todo, numa situação singular, pois aproxima-se simultaneamente de diversos universos simbólicos, deles se apropriando, mas, por outro, posiciona-se distintivamente com relação aos mesmos, buscando demarcar um espaço próprio, o que, em grande medida, relaciona-se à centralidade que as técnicas assumem nesse contexto e na eficácia que estas apresentariam, ainda que, diferentemente do que ocorre no campo médico, o paciente possui um papel ativo, de modo que o tratamento seria ineficaz sem a sua atuação.

Nesse universo das técnicas, a autora apresenta-nos uma primeira classificação, distinguindo as técnicas "preventivas", que produziriam efeitos terapêuticos, as "complementares", que tanto poderiam ser de diagnóstico como de tratamento, atuando em conjunto com uma técnica "alternativa", estas últimas constituiriam o eixo central do tratamento, e assim como as "complementares" podem ser tanto de diagnóstico como de tratamento. Todavia

[...] a definição de uma técnica como sendo preventiva, complementar, alternativa, de diagnóstico ou de tratamento, não pode desconsiderar a dinâmica de recomposição dessa rede, tanto no sentido de redefinir e ampliar o espectro de ação de antigas "especializações", como bem criar novas "especializações" (p. 73).

Os processos de arranjos e de legitimação das técnicas são os mais variáveis possíveis, verificando-se uma combinação bastante diversificada, ainda que algumas marcas sejam continuamente impressas, como a afirmação da necessidade de um certo "carisma" do terapeuta, para que o tratamento funcione, ainda que as técnicas sejam compreendidas como eficazes tanto a partir de um "empirismo terapêutico" como de uma cosmologia espiritualizante, e também por meio de uma crítica ao modelo biomédico, compreendido como unilateral.

A autora também apresenta uma reflexão interessante sobre as mudanças que essa rede terapêutica tem sofrido nas últimas décadas, desde o seu surgimento e visibilidade no Brasil a partir dos anos 1970 até os anos 1990, quando se pôde verificar uma maior profissionalização já iniciada nos anos 1980, o que se reflete tanto na 
formação dos terapeutas como nos próprios espaços onde as atividades se desenvolvem.

Ao se voltar para a análise dos agentes, a autora levanta como hipótese a ligação entre a formulação da identidade profissional do terapeuta e sua forma de entrada na rede. Ela aponta para quatro modelos, indo do menor ao maior grau de ruptura com o passado profissional do terapeuta. Nessa ordem, o primeiro modelo seria representado pela redefinição profissional "simpatizante", que seria a grande maioria dos casos encontrada pela pesquisadora, ocorrendo uma assimilação gradual de novas concepções terapêuticas em decorrência de uma insatisfação pessoal com o referencial terapêutico anterior; o segundo seria a transformação interna gradual, que se diferencia do anterior na medida em que a adesão dos valores de uma concepção "holística" da saúde parece se dar ao redirecionamento profissional; o terceiro seria a conversão "doce", formação de um público extremamente variado, quase todos com experiências anteriores no universo da Nova Era, mas que ao longo do trabalho de desenvolvimento espiritual acabou direcionando-se para a dimensão terapêutica; por fim, temos a conversão hard: trata-se de uma mudança profunda e radical com relação ao passado profissional, marcada por uma ruptura profunda, inesperada e involuntária. Para a autora há uma relação entre os perfis terapêuticos e a forma de entrada na rede.

Tavares indica a existência de dois perfis terapêuticos básicos: o espiritualizante e o psicologizante.

Cada um dos perfis apresenta características distintas, com graus variáveis de articulação interna, compondo um conjunto de posturas, concepções e "máximas" (p. 120).

Não se trata de uma interpretação dicotômica, pois os perfis se sobrepõem e dialogam, de modo que os terapeutas acabam por realizar combinações próprias espiritualizantes e psicologizantes. A autora aponta como pouco provável que o sujeito que ingressa na rede por meio redefinição profissional adote um perfil espiritualizante, e, no outro polo, aquele que ingressa por meio da conversão hard adote uma postura psicologizante: tais modelos representam os extremos das possibilidades postas na rede, cujos perfis terapêuticos possuem características distintas. Para ilustrar melhor as questões levantadas, ela explora de forma mais detalhada dois casos situados nesses limites, apontando, justamente, para essas diferenciações, mas destacando também como as articulações ocorrem na prática terapêutica, indicando que não se trata de polos estanques.

Com relação aos espaços, destaca-se a diversidade dos mesmo e como estes refletiam as transformações ocorridas nas últimas décadas, concentrados principalmente na 
Zona Sul carioca, estes são entendidos como "espaços alternativos", diferenciando-se da "clínica", onde ocorre a terapêutica convencional, do "consultório", onde um único profissional atua, e por fim, remetendo a uma dimensão "institucional". Também nesse caso a autora elabora uma classificação, apontando para três tipos básicos: os espaços terapêuticos, os esotérico-terapêuticos e os esotéricos, indo da dimensão mais terapêutica à mais comercial. Estes espaços diferenciam-se na decoração, indo daquela com menos elementos esotéricos àquela mais repleta de signos diversos, na regularidade das atividades, da maior para menor, uma gradação em termos de ênfase no atendimento e, por fim, variam da menor para a maior rotatividade de profissionais.

Também chamou a atenção da pesquisadora em seu trabalho de campo o fato de que os espaços mais "esotéricos" eram menos fechados no que tange à arregimentação de profissionais, contrapondo-se aos espaços terapêuticos mais fechados e, segundo a autora, mais preocupados com sua diferenciação e legitimação por meio de "profissionais sérios". Outro aspecto que ela destaca é a existência de uma "imprensa alternativa", que tendencialmente teria dado maior ênfase à questão terapêutica no decorrer dos anos 1990, divulgando técnicas, buscando sempre realizar uma abordagem mais "objetiva".

Tavares nos traz dois casos limites.

São experiências terapêuticas singulares e contrastivas; apresentam critérios de proximidade e distanciamento mais ou menos explícitos e que podem ser indicadores de critérios limites de legitimidade no âmbito da rede (p. 159).

O primeiro espaço é marcado por uma centralidade na terapia e, em última instância, na técnica em si, havendo parâmetros criteriosos para a seleção dos profissionais, bem como um intenso controle sobre a utilização das técnicas, aproximando-se das racionalidades médicas alternativas; o segundo, inversamente, apresenta parâmetros mais heterodoxos e, embora reconheça os critérios objetivos da técnica utilizada, por meio dos princípios ativos das ervas manipuladas, há uma centralidade bastante considerável no carisma daquela que produz as "gotinhas" utilizadas no tratamento ofertado, havendo, desse modo, uma maior aproximação com a medicina popular.

É apresentada em Alquimistas da cura a preocupação dos terapeutas não médicos em se legitimarem, uma construção que passa pela oposição ao trabalho considerado "não sério" e excessivamente "mágico". No âmbito desta questão, as tensões também se estabelecem com outros campos de saber, que aparentemente compreendem essas práticas como "pouco científicas", havendo destaque aqui para o 
papel assumido pelo Conselho Federal de Psicologia, já que muitos destes terapeutas anunciam suas práticas alternativas associadas à sua formação profissional em psicologia. Estas tensões que se estabelecem dinamizam-se ao longo dos anos 1990, o que se reflete na posição assumida pelo referido Conselho, que tendeu a recuar, sem assumir uma postura mais "fiscalizadora" com relação a estas atividades, o que se acompanhou também de um crescente processo de profissionalização desses terapeutas, bem como de institucionalização, refletindo a própria dinâmica da rede.

Essa "alquimia moderna" distribui-se entre dois campos de atuação possível: o "extramédico", alquimia relacionada à medicina popular; e o "paramédico", mais próximo de um modelo de legitimidade científica, que seria organizado em torno do conceito de "energia". Há enésimas possibilidade de articulação entre os elementos presentes entre os dois campos, bem como apresentam tensões diversas, de modo que há mais claramente um continuum que uma ruptura entre os dois polos.

Tavares dá relevo ao fato de que, apesar de apresentar uma homogeneidade discursiva mais clara, em torno do referencial holístico, ela também pode observar uma homogeneidade no âmbito das práticas, assim como a heterogeneidade não estaria presente apenas nestas, como também nos discursos, ou seja, homogeneidade e heterogeneidade, ainda que sejam mais visíveis em um nível que em outro, encontram-se nos dois.

Há de se destacar ainda que esse terapeutas diferenciam-se dos "curandeiros tradicionais" pois não se orientam por um referencial de ordem religiosa, sendo variados e sutis, indicando uma espiritualidade difusa. Há uma articulação clara entre a dimensão "espiritualizante" e a "terapêutica", ainda que ao compreender a existência nessa rede de uma "espiritualidade terapêutica" a enfase recaia sobre essa última dimensão, que redefine a própria espiritualidade.

O que podemos perceber ao longo desse trabalho, é que a construção dessa rede terapêutica, ainda inacabada mesmo no momento atual, coloca seus múltiplos agentes ante um campo de possibilidades e tensões, reelaboradas de várias formas, considerando aspectos como a biografia do sujeito, sua compreensão acerca das técnicas utilizadas, e sua própria posição diante das possibilidades postas. O trabalho de Tavares mostra um fôlego considerável que nos leva a refletir sobre a própria relação ambivalente que os sujeitos constroem a partir do projeto de modernidade, e ainda que se trate de um trabalho elaborado há mais de uma década, mostra-se ainda fundamental para a compreensão de alguns elementos do universo terapêutico e religioso no Brasil. 


\section{Referências}

AMARAL, Leila. Carnaval da alma: comunidade, essência e sincretismo na Nova Era. Petrópolis: Vozes, 2000.

BITTENCOURT FILHO, José. Matriz religiosa brasileira: religiosidade e mudança social. Petrópolis; Rio de Janeiro: Vozes; Koinonia, 2003.

OLIVEIRA, Amurabi. A Nova Era e New Age popular: transformações das religiões no Brasil. Cadernos de Pesquisa Interdisciplinar em Ciências Humanas, v. 11, 2011, p. 6585.

Corpos e corporeidade no universo da Nova Era. Revista Latinoamericana de Estudios sobre Cuerpos, Emociones y Sociedad, n. 9. 2012, p. 52-64. 